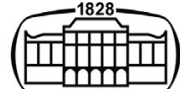

AKADÉMIAI KIADÓ

Journal of Behavioral Addictions

10 (2021) 1, 21-34

DOl:

$10.1556 / 2006.2021 .00012$

(c) 2021 The Author(s)

\section{FULL-LENGTH REPORT}

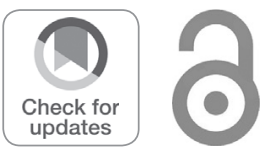

\title{
The identification of Australian low-risk gambling limits: A comparison of gambling-related harm measures
}

\author{
NICKI A. DOWLING ${ }^{1,2 *}$ (D, CHRISTOPHER J. GREENWOOD ${ }^{1,3}$, \\ STEPHANIE S. MERKOURIS ${ }^{1}$, GEORGE J. YOUSSEF ${ }^{1,3}$, \\ MATTHEW BROWNE ${ }^{4}$, MATTHEW ROCKLOFF ${ }^{4}$ and \\ PAUL MYERS ${ }^{5}$ \\ ${ }^{1}$ School of Psychology, Deakin University, Geelong, VIC 3220, Australia \\ ${ }^{2}$ Melbourne Graduate School of Education, University of Melbourne, Parkville, VIC 3010, Australia \\ ${ }^{3}$ Centre for Adolescent Health, Murdoch Children's Research Institute, Melbourne, Australia \\ ${ }^{4}$ Experimental Gambling Research Laboratory, CQUniversity, Bundaberg, QLD, Australia \\ ${ }^{5}$ The Social Research Centre, Australian National University, Melbourne, VIC 3000, Australia
}

Received: September 22, 2020 • Revised manuscript received: January 11, 2021; February 09, 2021 • Accepted

February 12, 2021

Published online: March 31, 2021

\begin{abstract}
Background and aims: Problem gambling severity and gambling-related harm are closely coupled, but conceptually distinct, constructs. The primary aim was to compare low-risk gambling limits when gambling-related harm was defined using the negative consequence items of the Problem Gambling Severity Index (PGSI-Harm) and the Short Gambling Harms Scale items (SGHS-Harm). A secondary aim was compare low-risk limits derived using a definition of harm in which at least two harms across different domains (e.g. financial and relationship) were endorsed with a definition of harm in which at least two harms from any domain were endorsed. Methods: Data were collected from dual-frame computer-assisted telephone interviews of 5,000 respondents in the fourth Social and Economic Impact Study (SEIS) of Gambling in Tasmania. Receiver operating characteristic (ROC) curve analyse were conducted to identify low-risk gambling limits. Results: PGSI-Harm and SGHS-Harm definitions produced similar overall limits: $30-37$ times per year; AUD $\$ 510-\$ 544$ per year; expenditure comprising no more than $10.2-10.3 \%$ of gross personal income; $400-454$ minutes per year; and 2 types of gambling activities per year. Acceptable limits (AUC $\geq 0.70$ ) were identified for horse/dog racing, keno, and sports/other betting using the PGSI definition; and electronic gaming machines, keno, and bingo using the SGHS definition. The requirement that gamblers endorse two or more harms across different domains had a relatively negligible effect. Discussion and conclusions: Although replications using alternative measures of harm are required, previous PGSI-based limits appear to be robust thresholds that have considerable potential utility in the prevention of gambling-related harm.
\end{abstract}

\section{KEYWORDS}

low-risk limits, low-risk guidelines, gambling, responsible gambling, gambling harm, gambling-related harm

\section{INTRODUCTION}

The public health perspective, which frames gambling within a whole of population approach to inform policy for prevention and intervention practices, involves identifying determinants and subsequent harms of problematic gambling behaviour (Korn \& Shaffer, 1999). Langham et al. (2016) functionally defined gambling-related harm as 'any initial or exacerbated adverse consequence due to an engagement with gambling that leads to a decrement to the health or wellbeing of an individual, family unit, community or population'. They developed a 
conceptual framework that organised harms across broad domains: financial harm; relationship disruption, conflict or breakdown; emotional or psychological distress; decrements to health; cultural harm; reduced performance at work or study; and non-normative/criminal activity. Problem gambling severity and harm are closely coupled but conceptually distinct constructs, and harm that occurs below the clinical threshold of pathology is still relevant to policy (Browne \& Rockloff, 2017; Delfabbro \& King, 2019). Thus, a harm-reduction approach tends to be more focused on preventing harmful gambling rather than preventing the psychiatric condition of disordered gambling (Currie et al., 2006; Currie, Miller, Hodgins, \& Wang, 2009).

In the alcohol field, low-risk drinking limits have been developed to distinguish between low and high-risk drinking behaviour (Room \& Rehm, 2012). Although these limits have been subject to some criticism (Casswell, 2012; Room \& Rehm, 2012), they serve as the basis for low-risk drinking guidelines that are promoted to the general public to help individuals make informed choices about their drinking habits and their associated risks (National Health and Medical Research Council [NHMRC], 2020; Room \& Rehm, 2012). In contrast, there has been very little empirical research attempting to define levels of low-risk gambling, despite findings that many gamblers attempt to reduce their gambling by setting frequency, expenditure, and time limits (Currie, Hodgins, Wang, El-Guebaly, Wynne, et al., 2008). Gambling stakeholders and the general public believe that empirically-derived low-risk limits are important in preventing gambling-related harm (Currie, Hodgins, Wang, El-Guebaly, \& Wynne, 2008; Dowling et al., 2018).

To date, all low-risk gambling limits in populationrepresentative samples have been identified using a risk ratio approach involving receiver operating characteristic (ROC) analyses (Brosowski et al., 2015; Currie et al., 2017; Currie et al., 2006; Currie, Hodgins, Wang, El-Guebaly, Wynne, et al., 2008; Currie et al., 2009; Dowling et al., 2018; Dowling et al., 2021). In Australia, Dowling et al. (2021) recently derived a set of overall low-risk gambling limits across population-representative telephone surveys conducted in Tasmania (the second and third Social and Economic Impact Study (SEIS) of Gambling in Tasmania) and the Australian Capital Territory (ACT: 2014 Survey on Gambling, Health, and Wellbeing in the ACT): gambling frequency of 20-30 times per year; gambling expenditure of AUD\$380-\$615 per year (USD $\$ 240-\$ 388$ per year); gambling expenditure comprising $0.83-1.68 \%$ of gross personal income; and participating in no more than 2 types of gambling activities per year. In this study, similar limits were identified from these two disparate Australian states and territories. The ACT limits were, however, consistently slightly more conservative than the Tasmanian limits, which is not unexpected given that the ACT population is characterised by slightly lower rates of gambling participation and a higher socio-economic profile (e.g. higher levels of working age people, employment, education and income (Dowling et al., 2021)). The findings indicated that a considerable proportion of gamblers exceeding a particular limit also exceeded other limits and the two gambling expenditure limits (gambling expenditure and gambling expenditure as a proportion of income) were consistently the best-performing.

Several studies have also derived low-risk limits for gamblers participating in specific gambling activities (Brosowski et al., 2015; Quilty, Murati, \& Bagby, 2014). In a combined psychiatric outpatient and community sample, Quilty et al. (2014) identified low-risk gambling limits for instant scratch tickets (gambling for more than once per month), bingo (gambling for no longer than 135 minutes per session and spending no more than CAD $\$ 450$ per year), casino table games (gambling for no more than never, gambling for no longer than 190 minutes per session, and spending no more than CAD $\$ 330-C A D \$ 1,200$ per year), and sports betting (spending no more than CAD $\$ 510-C A D \$ 780$ per year). Brosowski et al. (2015) subsequently identified some activity-specific limits in a representative dual-frame German dataset: electronic gaming machines (EGMs) (gambling no more than 3 days in the last year and no more than 10-days ever) and poker (nor more than 1-10 days ever).

These previous efforts to develop low-risk gambling limits have defined gambling-related harm using item subsets of problem gambling severity measures, predominantly the Problem Gambling Severity Index (PGSI: Ferris \& Wynne, 2001) (Brosowski et al., 2015; Currie et al., 2017; Currie et al., 2006; Currie, Hodgins, Wang, El-Guebaly, Wynne, et al., 2008; Currie et al., 2009; Dowling et al., 2018; Dowling et al., 2021; Quilty et al., 2014). It has been argued the PGSI is a viable instrument to measure gambling-related harm because it has some focus on negative consequences rather than only behavioural symptoms (Currie et al., 2009). This measure, however, comprises only a limited number of negative consequence items and there is some disagreement regarding which items are negative consequences (Browne \& Rockloff, 2019a; Currie, Hodgins, Wang, El-Guebaly, Wynne, et al., 2008; Currie et al., 2009; Ferris \& Wynne, 2001). Moreover, some definitions of harm in the literature are based on only the negative consequence items (Currie et al., 2017; Currie et al., 2006; Currie, Hodgins, Wang, El-Guebaly, Wynne, et al., 2008; Dowling et al., 2018; Dowling et al., 2021) while others are based on all PGSI items (Currie et al., 2006; Currie, Hodgins, Wang, El-Guebaly, Wynne, et al., 2008; Currie et al., 2009; Dowling et al., 2018). Arguably, the PGSI includes items measuring financial, relationship, emotional/psychological, and health harms (Browne \& Rockloff, 2019a), but does not assess harms across other domains. The exclusive reliance on measures of problem gambling severity to measure harm is a limitation in this literature compared with the alcohol literature, which has employed a range of harms to the drinker, including chronic disease from the volume of drinking over time, injury from specific drinking occasions, total mortality, hazardous behaviours, and delinquent behaviours (National Health and Medical Research Council [NHMRC], 2009; Room \& Rehm, 2012).

Moreover, previous studies have been characterised by a lack of consensus on an aggregate limit of gambling-related harm using problem gambling severity measures. Although 
low-risk limits have generally been robust to variations in definitions of harm (Brosowski et al., 2015; Currie et al., 2006; Currie, Hodgins, Wang, El-Guebaly, Wynne, et al., 2008; Currie et al., 2009; Dowling et al., 2018), superior ROC psychometric properties have generally been produced when gambling-related harm is defined as two or more negative consequences (Currie et al., 2006; Currie, Hodgins, Wang, El-Guebaly, Wynne, et al., 2008; Currie et al., 2009; Dowling et al., 2018). It has, however, been argued that people endorsing gambling-related problems in two different domains can reasonably be viewed as beginning to experience harm related to their gambling (Currie et al., 2006). To date, however, all available population-level research have employed $2+$ harm definitions in which at least two harms from any domain are endorsed (Currie et al., 2017; Currie et al., 2006; Currie, Hodgins, Wang, El-Guebaly, Wynne, et al., 2008; Dowling et al., 2018; Dowling et al., 2021). There is therefore a need for research to explore the effect of using a definition of harm in which at least two harms across different domains are endorsed.

\section{Study aims}

Given that problem gambling severity and gambling-related harm are not synonymous (Browne \& Rockloff, 2017; Delfabbro \& King, 2019), there is a need to identify low-risk gambling limits using alternative measures of gamblingrelated harm (Dowling et al., 2018, 2021). To date, this important advance has been hindered by the absence of validated measures of harms attributable to gambling with interpretable scoring procedures. Browne, Goodwin, and Rockloff (2018), however, have recently developed and validated a new brief instrument, the Short Gambling Harms Scale (SGHS), for use as a population-level measure of pastyear gambling-related harm. The primary aim of this study was to compare the overall and activity-specific low-risk gambling limits identified for the Tasmanian population when gambling-related harm was defined using the negative consequence items of the PGSI (PGSI-Harm) and the SGHS items. A secondary aim was to compare low-risk limits derived using a definition of harm in which at least two harms across different domains (e.g. financial and relationship) were endorsed with a definition of harm in which at least two harms from any domain were endorsed.

\section{METHODS}

\section{Participants and procedure}

Secondary analysis of population data from the fourth Social and Economic Impact Study (SEIS) of Gambling in Tasmania (ACIL Allen, Deakin University, Central Queensland University, \& Social Research Centre, 2017) was conducted. This study was selected for analysis as it was the first available population-representative study in Australia to collect gambling-related harms using the SGHS, as well as collect continuous expenditure data across multiple gambling activities. Data was collected via Computer
Assisted Telephone Interviews (CATIs) with 5,000 residents of Tasmania aged 18 years and over from 13 June to 7 August 2017 (see Table 1 for descriptive statistics). Due to a focus on state-level estimates, the collected sample was stratified according to broad geographic regions in proportion to the population. A dual-frame sample design was employed, with a 50\% landline phone and 50\% mobile phone split. The sample was drawn from three sources: random digit dial (RDD) landline, pre-screened RDD mobile sample and listed mobile phone numbers. Respondents for the landline sample were selected using the youngest male aged 18 years and over method, while respondents for the mobile phone samples were taken to be

Table 1. Sample descriptive statistics

\begin{tabular}{|c|c|}
\hline Characteristic & Proportion $(95 \% \mathrm{CI})$ \\
\hline Gender (male) & $48.8 \%(47.1,50.6)$ \\
\hline \multicolumn{2}{|l|}{ Age (years) } \\
\hline $18-24$ & $11.1 \%(9.5,12.8)$ \\
\hline $25-34$ & $15.1 \%(13.6,16.8)$ \\
\hline $35-44$ & $15.1 \%(13.8,16.4)$ \\
\hline $45-54$ & $17.2 \%(16.0,18.4)$ \\
\hline $55-64$ & $17.7 \%(16.7,18.8)$ \\
\hline $65+$ & $23.8 \%(22.7,25.0)$ \\
\hline \multicolumn{2}{|l|}{ Household structure } \\
\hline Couple with no children & $10.5 \%(9.5,11.7)$ \\
\hline Couple with children still at home & $34.5 \%(32.8,36.3)$ \\
\hline $\begin{array}{l}\text { Couple with children not living at } \\
\text { home }\end{array}$ & $21.5 \%(20.3,22.7)$ \\
\hline $\begin{array}{l}\text { Single person household (no } \\
\text { children) }\end{array}$ & $10.8 \%(9.9,11.8)$ \\
\hline Single with children still at home & $7.4 \%(6.5,8.6)$ \\
\hline $\begin{array}{l}\text { Single with children not living at } \\
\text { home }\end{array}$ & $6.5 \%(5.9,7.1)$ \\
\hline Group or shared household & $4.5 \%(3.7,5.5)$ \\
\hline In some other arrangement & $4.2 \%(3.5,5.0)$ \\
\hline \multicolumn{2}{|l|}{ Occupational status } \\
\hline Paid full-time employed & $32.6 \%(31.0,34.3)$ \\
\hline Paid part-time employed & $21.9 \%(20.4,23.4)$ \\
\hline Looking for work & $3.7 \%(3.0,4.7)$ \\
\hline Not in the labour force & $41.8 \%(40.1,43.5)$ \\
\hline \multicolumn{2}{|l|}{ Educational attainment } \\
\hline Less than secondary school & $22.3 \%(20.9,23.7)$ \\
\hline Secondary school & $20.9 \%(19.3,22.5)$ \\
\hline Vocational or trade qualification & $40.8 \%(39.0,42.5)$ \\
\hline University graduate & $16.0 \%(15.1,17.1)$ \\
\hline \multicolumn{2}{|l|}{ Country of birth (Australia) } \\
\hline Australia & $85.8 \%(84.6,86.9)$ \\
\hline \multicolumn{2}{|l|}{$\begin{array}{l}\text { Problem Gambling Severity Index } \\
\text { category }\end{array}$} \\
\hline Non-gambling & $41.5 \%(39.8,43.3)$ \\
\hline Non-problem gambling & $51.8 \%(50.0,53.5)$ \\
\hline Low-risk gambling & $4.8 \%(4.0,5.6)$ \\
\hline Moderate-risk gambling & $1.4 \%(1.0,1.9)$ \\
\hline Problem gambling & $0.6 \%(0.4,1.0)$ \\
\hline $\begin{array}{l}\text { Problem Gambling Severity Index } \\
\text { score - M (SD) }\end{array}$ & $0.2(1.5)$ \\
\hline $\begin{array}{l}\text { Short Gambling Harms Scale score - } \\
\text { M (SD) }\end{array}$ & $0.1(1.0)$ \\
\hline
\end{tabular}


any person who answered the phone, was a resident of Tasmania and was 18 years of age or older.

A total of 90,315 calls were placed to 26,476 sample records to achieve 5,000 interviews. Using the American Association for Public Opinion Research [AAPOR] Response Rate 3, which proportionally allocates records with an unknown outcome as either in-scope or out-of-scope based on the distribution of records with a known call outcome (American Association of Public Opinion Research, 2011), the final combined response rate for the survey was $41.5 \%$. A pilot test of 50 interviews was undertaken to ensure internal logic. A 2-stage approach to weighting was undertaken: (1) calculation of a design weight to adjust for the probability of being sampled by landline and mobile phone and (2) adjusting this weight by iterative proportion fitting so the final weight conformed to population benchmarks for telephone status, age, sex, region, education and country of birth. The average interview duration was 15 minutes.

\section{Measures}

Gambling consumption indices and measures of harm. The overall and activity-specific low-risk gambling limits were derived on the basis of multiple indices of gambling consumption (Table 2) and using items from the PGSI and SGHS. The 9-item PGSI (Ferris \& Wynne, 2001) has been adopted as the preferred instrument for measuring problem gambling severity in population-level research in Australia and generally displays good psychometric properties (Currie, Hodgins, \& Casey, 2013; Ferris \& Wynne, 2001; Neal, Delfabbro, \& O'Neil, 2005). The PGSI negative consequence items are identified in Table 3. The 10-item SGHS (Browne et al., 2018) was developed for use as a population-level measure of past year gambling-related harm to monitor the impact of gambling on the community. The SGHS was based on an initial item pool of 72 specific harms caused by problematic gambling and validated using an internet panel sample of 1,524 past year gamblers. Ten items were selected using an item selection algorithm with the goals of maximising sensitivity and construct coverage. Each has a binary response option and total scores are calculated by summing the number of endorsed items. The SGHS is highly correlated with the 72 -item checklist $(0.94)$ and achieves a very small percentage of false negatives in terms of identifying persons otherwise harmed by gambling (4.8\%). It displays very strong reliability $(\alpha=0.93$; coefficient omega $=0.83)$, homogeneity and unidimensionality; and significant associations with the PGSI, gambling consumption, lower quality of life, and addictive gambling symptoms.

Definitions of gambling-related harm. For the primary aim, endorsement of two or more of the seven negative consequence PGSI items (PGSI-Harm) was compared to endorsement of two or more SGHS items (SGHS-Harm). For the secondary aim, harm domains were operationalised using the combined set of PGSI negative consequence items and SGHS items (Table 3); and endorsement of two or more items across any domain of harm (Any-domain-Harm) was

Table 2. Gambling consumption indices ${ }^{\mathrm{a}}$

\begin{tabular}{c}
\hline Tymbling frequency, c \\
12 months, how many times per \\
week, per month or per year \\
have you played/bet on \\
[gambling activity]?' for \\
different modalities (e.g. venue, \\
telephone, racetrack, off-course \\
venue, internet on mobile \\
device, internet using desktop \\
computer) of each gambling \\
activity. Annual gambling \\
frequency was calculated by \\
standardising each response to \\
an estimated yearly frequency \\
then summing these yearly \\
frequencies across gambling \\
activities.
\end{tabular}

Gambling expenditure ${ }^{b, c}$, session expenditure ${ }^{c}$

Gambling expenditure as a proportion of gross annual personal income ${ }^{\mathrm{b}, \mathrm{c}}$
Typical wording was: 'In the past 12 months, approximately how much money, on average, did you spend during each session of [gambling activity]?' for each specific gambling activity. Total annual gambling expenditure was calculated by multiplying gambling frequency with session expenditure estimates for each activity then summing these yearly gambling expenditures across all gambling activities. Gambling expenditure was assessed only in terms of amount of money lost.

Gross annual personal income was assessed: 'Could you please tell me your approximate annual personal income before tax?' In contrast to previous Tasmanian SEIS surveys, categories were refined to $\$ 10,000$ increments for the purposes of these analyses (from less than $\$ 10,000$ to $\$ 150,000$ or more). To derive expenditure as a proportion of income, we used the mid-point of each category's range to represent the respective income category (e.g. $\$ 10,000$ to $\$ 19,999$ became $\$ 15,000)$. For the final income category (e.g. $\$ 150,000$ or more) in which no mid-point exists, the same

$\$ 5,000$ interval that was applied (i.e. \$155,000). Total annual gambling expenditure was then divided by the mid-point income value to derive gambling expenditure as a

(continued) 
Table 2. Continued

\begin{tabular}{cc}
\hline & proportion of income. A small \\
number $(n=4)$ of estimates \\
exceeding $100 \%$ were removed \\
from the dataset. \\
The number of types of \\
$\begin{array}{c}\text { Number of types of gambling } \\
\text { activities }\end{array}$ \\
gambling activities was based on \\
participation across each \\
gambling activity, with the \\
exception of informal private \\
games due to low participation. \\
Typical wording was: 'I am \\
going to start by reading a list of \\
popular gambling activities and \\
find out if you have played them \\
for money in the previous 12 \\
months. In the last 12 months, \\
have you...?' \\
Typical wording was: "In the \\
past 12 months, how much time \\
on average did you spend \\
playing/betting on [gambling \\
activity] during each visit/ \\
session/transaction of \\
[gambling activity]". Responses \\
duration ${ }^{c}$
\end{tabular}

${ }^{a}$ Unless otherwise indicated all gambling indices were based on estimates from nine gambling activities: EGMs, horse or greyhound racing, instant scratch tickets, lotteries, keno, casino table games, bingo, sports or other event betting, and informal private games.

${ }^{\mathrm{b}}$ Gambling consumption index for overall low-risk gambling limits.

${ }^{c}$ Gambling consumption index for activity-specific limits.

compared to endorsement of two or more harms across different domains (Cross-domain-Harm).

\section{Data analytic strategy}

All analyses employed weighted data and were conducted in Stata-14 (StataCorp, 2015). ROC analyses were conducted to identify optimal low-risk gambling limits across the multiple gambling consumption indices and definitions of harm. In these ROC analyses, the sensitivity and 1-specificity for each level of gambling consumption index was plotted and the area under the curve (AUC) of the resulting graph was calculated. AUC values were interpreted according to established guidelines: low (0.50-0.70), moderate (0.70-0.90), and high (>0.90) (Swets, Dawes, \& Monahan, 2000). In this study, optimal cut-offs displaying moderate to high classification accuracy (AUC value $\geq 0.70$ ) were considered acceptable (Brosowski et al., 2015; Swets et al., 2000). The level of gambling behaviour that had the
Table 3. Operationalisation of harm domains using PGSI negative consequence items and SGHS items

\begin{tabular}{|c|c|c|}
\hline Category & Measure & Item \\
\hline \multirow[t]{8}{*}{ Financial } & PGSI & $\begin{array}{c}\text { Bet more than you could really } \\
\text { afford to lose }\end{array}$ \\
\hline & PGSI & $\begin{array}{l}\text { Borrowed money or sold } \\
\text { anything to get money to gamble }\end{array}$ \\
\hline & PGSI & $\begin{array}{l}\text { Gambling has caused any } \\
\text { financial problems for you or } \\
\text { your household }\end{array}$ \\
\hline & SGHS & $\begin{array}{c}\text { Reduction of your available } \\
\text { spending money }\end{array}$ \\
\hline & SGHS & Reduction of your savings \\
\hline & SGHS & $\begin{array}{l}\text { Less spending on recreational } \\
\text { expenses such as eating out, } \\
\text { going to movies or other } \\
\text { entertainment. }\end{array}$ \\
\hline & SGHS & Sold personal items \\
\hline & SGHS & Increased credit card debt \\
\hline \multirow[t]{2}{*}{ Relationship } & PGSI & $\begin{array}{c}\text { Felt people criticised your } \\
\text { betting or told you that you had } \\
\text { a gambling problem, regardless } \\
\text { of whether or not you thought it } \\
\text { was true }\end{array}$ \\
\hline & SGHS & $\begin{array}{c}\text { Spent less time with people you } \\
\text { care about }\end{array}$ \\
\hline \multirow[t]{6}{*}{$\begin{array}{l}\text { Emotional/ } \\
\text { Psychological }\end{array}$} & PGSI & $\begin{array}{l}\text { Felt that you might have a } \\
\text { problem with gambling }\end{array}$ \\
\hline & PGSI & $\begin{array}{c}\text { Felt guilty about the way you } \\
\text { gamble, or what happens when } \\
\text { you gamble }\end{array}$ \\
\hline & SGHS & $\begin{array}{l}\text { Had regrets that made you feel } \\
\text { sorry about your gambling }\end{array}$ \\
\hline & SGHS & Felt ashamed of your gambling \\
\hline & SGHS & $\begin{array}{c}\text { Felt distressed about your } \\
\text { gambling }\end{array}$ \\
\hline & SGHS & Felt like a failure \\
\hline Health & PGSI & $\begin{array}{l}\text { Gambling has caused you any } \\
\text { health problems, including a } \\
\text { feeling of stress or anxiety }\end{array}$ \\
\hline
\end{tabular}

maximum Youden Index value (Youden, 1950), relative to all other levels of gambling behaviour, was deemed the optimal cut-off (with equal weighting given to sensitivity and specificity) (see Ruopp, Perkins, Whitcomb, \& Schisterman, 2008). Missing data were removed via pairwise deletion. Missing data was low for key gambling consumption and harm variables (range $<1-3 \%$ ), except expenditure as a proportion of income (11\%). This was due to the high rate of missing data for income, which is very common in large population-based research (Kim, Egerter, Cubbin, Takahashi, \& Braveman, 2007) due to respondents considering income information too private or sensitive and not knowing their income (Davern, Rodin Beebe, \& Call, 2005). This statistical approach replicated that employed in Dowling et al. (2021) in order to facilitate direct comparisons to the overall lowrisk, limits derived from the PGSI in the second and third SEIS studies of Gambling in Tasmania and the 2014 Survey on Gambling, Health and Wellbeing in the ACT. 
In the first set of ROC analyses, overall low-risk gambling limits were identified in the sample of past-year gamblers for PGSI-Harm and SGHS-Harm. In the second set of ROC analyses, low-risk gambling limits for each gambling activity (see Table 2) were identified using PGSIHarm and SGHS-Harm in samples of respondents who reported past-year participation in each specific gambling activity (e.g. EGM limits were derived using only EGM gamblers) and with consumption measures specific to each activity (e.g. EGM expenditure not overall gambling expenditure). In the third set of ROC analyses, overall low-risk gambling limits were identified in the sample of past-year gamblers using Any-domain-Harm and Crossdomain-Harm. Further characterisation of the low-risk limits is presented in terms of absolute risk (i.e., proportion of people who were above the limit who experienced harm) and risk ratio (i.e., ratio of the incidence rate in individuals who were above the limit, relative to the incidence rate in individuals who were below the limit). The data analysis scripts for this study can be found on the Open Science Framework (https://osf.io/qu85y/).

\section{Ethics}

This project was approved by the Deakin University Human Research Ethics Committee (2017-145). Respondents were informed about the study and all provided informed consent.

\section{RESULTS}

\section{PGSI and SGHS definitions of harm: Overall low-risk gambling limits}

The overall low-risk gambling limits were all acceptable using both PGSI-Harm and SGHS-Harm, with all displaying similar moderate classification accuracy (Table 4). PGSIHarm was exceeded by $3.9 \%$ of gamblers and $2.3 \%$ of the population. Using this definition, the overall limits were exceeding any of the following: gambling frequency of 37 times per year; gambling expenditure of AUD $\$ 544$ per year; gambling expenditure comprising $10.32 \%$ of gross personal income; gambling duration of 454 minutes ( $7 \mathrm{~h}, 34 \mathrm{~min}$ ) per year; and 2 types of gambling activity per year. The proportion of gamblers who exceeded these limits and reported harm ranged from 5.8 to $24.0 \%$; while exceeding these limits was associated with a 4.3 -fold-9.8-fold increase in the risk of experiencing harm, relative to gamblers who did not exceed the limits.

Similarly, SGHS-Harm was exceeded by $4.5 \%$ of gamblers and $2.6 \%$ of the population. Using this definition, the overall limits were exceeding any of the following: gambling frequency of 30 times per year; gambling expenditure of AUD\$510 per year; gambling expenditure comprising 10.2\% of gross personal income; gambling duration of 400 minutes ( $6 \mathrm{~h}, 40 \mathrm{~min}$ ) per year; and 2 types of gambling activities per year. The proportion of gamblers who exceeded these limits and who reported harm ranged from 6.6 to $22.4 \%$; while exceeding these limits was associated with a 3.2-fold to 6.8 -fold increase in the risk of experiencing harm, relative to gamblers who did not exceed the limits.

Across all true positive cases, $38-56 \%$ were true positives for both PGSI-Harm and SGHS-Harm: gambling frequency per year $=38 \%$; gambling expenditure per year $=41 \%$; gambling expenditure a proportion of gross personal income $=56 \%$; gambling duration per year $=47 \%$; number of types of gambling activities $=39 \%$. There was, however, considerable overlap in those exceeding the overall low-risk gambling limits using PGSI-Harm and SGHS-Harm. Over $90 \%$ of respondents exceeding the SGHS-Harm limits also exceeded the PGSI-Harm limits: gambling frequency per year $=94 \%$; gambling expenditure per year $=92 \%$; gambling expenditure a proportion of gross personal income $=100 \%$; gambling duration per year $=94 \%$; number of types of gambling activities $=100 \%$.

\section{PGSI and SGHS definitions of harm: Activity-specific limits}

Few of the optimal low-risk gambling limit cut-offs identified for specific gambling activities displayed acceptable levels of discrimination, using either PGSI-Harm (Table 5) or SGHS-Harm (Table 6), with most displaying low classification accuracy. The limits relating to gambling frequency per year, gambling expenditure per year, and session expenditure yielded acceptable levels of classification performance for PGSI-Harm, while the limits relating to gambling expenditure and gambling duration per year were the most likely to be acceptable for SGHS-Harm.

Using PGSI-Harm, acceptable activity-specific limits were identified for horse/dog race gambling (16 times per year, AUD\$450 per year, $7.0 \%$ of gross personal income, 380 minutes per year, AUD\$25 per session, 25 minutes per session), keno (11 times per year, AUD $\$ 150$ per year), and sports/other event betting (AUD\$25 per session). This definition of harm was exceeded by $8.2 \%$ of horse or dog race gamblers, $5.9 \%$ of keno players, and $15.5 \%$ of sports or other event bettors. The proportion of gamblers who exceeded these limits and who reported harm ranged from 11.8 to $30.8 \%$; while exceeding these limits was associated with a 3.3 -fold to 11.5 -fold increase in the risk of experiencing harm, relative to gamblers who did not exceed the limits.

Using SGHS-Harm, acceptable activity-specific limits were identified for EGM gambling (AUD\$240 per year, 330 minutes per year, AUD\$30 per session), keno (11 times per year, $\$ 130$ per year, 135 minutes per year), and bingo (6 times per year, \$120 per year, 360 minutes per year, \$20 per session, 90 minutes per session). This definition of harm was exceeded by $9.8 \%$ of EGM gamblers, $6.91 \%$ of keno players, and $8.3 \%$ of bingo players. The proportion of gamblers who exceeded these limits and who reported harm ranged from 11.0 to $23.2 \%$; while exceeding these limits was associated with a 2.5 -fold to 10.0 -fold increase in the risk of experiencing harm, relative to gamblers who did not exceed the limits. 
Table 4. Identification of overall low-risk gambling limits using each definition of gambling-related harm ${ }^{\mathrm{a}}$

\begin{tabular}{|c|c|c|c|c|c|}
\hline Low-risk gambling limit & & PGSI-Harm ${ }^{\text {b }}$ & SGHS-Harm ${ }^{c}$ & $\begin{array}{l}\text { Any-domain- } \\
\text { Harm }^{\mathrm{d}}\end{array}$ & $\begin{array}{l}\text { Cross-domain- } \\
\text { Harm }^{\mathrm{e}}\end{array}$ \\
\hline $\begin{array}{l}\text { Proportion of population } \\
\text { (including non-gamblers) } \\
\text { exceeding each definition } \\
\text { of harm }\end{array}$ & & $\begin{array}{c}2.26 \%(95 \% \mathrm{CI} \\
1.74,2.94)\end{array}$ & $\begin{array}{c}2.63 \%(95 \% \text { CI } \\
2.11,3.28)\end{array}$ & $\begin{array}{c}4.24 \%(95 \% \text { CI } \\
3.53,5.08)\end{array}$ & $\begin{array}{c}3.29 \%(95 \% \mathrm{CI} \\
2.67,4.06)\end{array}$ \\
\hline $\begin{array}{l}\text { Proportion of gamblers } \\
\text { exceeding each definition } \\
\text { of harm }\end{array}$ & & $\begin{array}{l}3.87 \%(95 \% \mathrm{CI} \\
2.98,5.01)\end{array}$ & $\begin{array}{l}4.51 \%(95 \% \mathrm{CI} \\
3.62,5.61)\end{array}$ & $\begin{array}{l}7.25 \%(95 \% \mathrm{CI} \\
6.06,8.66)\end{array}$ & $\begin{array}{c}5.63 \%(95 \% \mathrm{CI} \\
4.58,6.92)\end{array}$ \\
\hline \multirow[t]{6}{*}{ Gambling frequency per year } & Cut-off & 37 & 30 & 29 & 33 \\
\hline & AUC (95\% CIs) & $0.75(0.66,0.84)$ & $0.75(0.68,0.81)$ & $0.72(0.66,0.78)$ & $0.72(0.66,0.79)$ \\
\hline & $\begin{array}{l}\text { Sensitivity, } \\
\text { specificity }\end{array}$ & $0.64,0.73$ & $0.69,0.68$ & $0.65,0.67$ & $0.62,0.70$ \\
\hline & $N$ & 2,792 & 2,781 & 2,793 & 2,793 \\
\hline & Absolute risk & 7.4 & 7.8 & 11.9 & 9.9 \\
\hline & Relative risk & 4.3 & 3.2 & 2.8 & 3.3 \\
\hline \multirow{6}{*}{$\begin{array}{l}\text { Gambling expenditure per } \\
\text { year }\end{array}$} & Cut-off & 544 & 510 & 440 & 501 \\
\hline & AUC (95\% CIs) & $0.79(0.72,0.71)$ & $0.79(0.73,0.85)$ & $0.77(0.72,0.81)$ & $0.77(0.71,0.83)$ \\
\hline & $\begin{array}{l}\text { Sensitivity, } \\
\text { specificity }\end{array}$ & $0.72,0.71$ & $0.73,0.70$ & $0.71,0.68$ & $0.69,0.70$ \\
\hline & $N$ & 2,708 & 2,697 & 2,709 & 2,709 \\
\hline & Absolute risk & 8.6 & 9.0 & 13.2 & 10.9 \\
\hline & Relative risk & 5.3 & 4.8 & 3.7 & 4.0 \\
\hline \multirow{6}{*}{$\begin{array}{l}\text { Gambling expenditure a } \\
\text { proportion of gross } \\
\text { personal income }\end{array}$} & Cut-off & 10.3 & 10.2 & 9.4 & 9.8 \\
\hline & AUC (95\% CIs) & $0.73(0.67,0.79)$ & $0.71(0.65,0.76)$ & $0.68(0.64,0.72)$ & $0.70(0.66,0.75)$ \\
\hline & $\begin{array}{l}\text { Sensitivity, } \\
\text { specificity }\end{array}$ & $0.55,0.92$ & $0.53,0.93$ & $0.48,0.91$ & $0.52,0.92$ \\
\hline & $N$ & 2,310 & 2,303 & 2,311 & 2,311 \\
\hline & Absolute risk & 24.0 & 22.4 & - & 30.4 \\
\hline & Relative risk & 9.8 & 6.8 & - & 8.0 \\
\hline \multirow{6}{*}{$\begin{array}{l}\text { Gambling duration per year } \\
\text { (minutes) }\end{array}$} & Cut-off & 454 & 400 & 353 & 410 \\
\hline & AUC (95\% CIs) & $0.77(0.68,0.86)$ & $0.76(0.69,0.83)$ & $0.75(0.70,0.81)$ & $0.77(0.70,0.84)$ \\
\hline & $\begin{array}{l}\text { Sensitivity, } \\
\text { specificity }\end{array}$ & $0.65,0.76$ & $0.65,0.73$ & $0.65,0.73$ & $0.65,0.75$ \\
\hline & $N$ & 2,787 & 2,777 & 2,788 & 2,788 \\
\hline & Absolute risk & 11.1 & 11.2 & 18.9 & 14.3 \\
\hline & Relative risk & 7.9 & 5.7 & 5.3 & 5.9 \\
\hline \multirow{6}{*}{$\begin{array}{l}\text { Number of types of gambling } \\
\text { activities }\end{array}$} & Cut-off & 2 & 2 & 2 & 2 \\
\hline & AUC (95\% CIs) & $0.75(0.69,0.81)$ & $0.75(0.69,0.81)$ & $0.75(0.71,0.80)$ & $0.74(0.69,0.79)$ \\
\hline & $\begin{array}{l}\text { Sensitivity, } \\
\text { specificity }\end{array}$ & $0.78,0.58$ & $0.77,0.58$ & $0.76,0.60$ & $0.75,0.59$ \\
\hline & $N$ & 2,833 & 2,822 & 2,834 & 2,834 \\
\hline & Absolute risk & 5.8 & 6.6 & 10.6 & 8.2 \\
\hline & Relative risk & 6.1 & 4.2 & 4.5 & 4.5 \\
\hline
\end{tabular}

${ }^{\mathrm{a}}$ Bold typeface indicates AUC $\geq 0.70$.

${ }^{\mathrm{b}}$ Endorsement of $\geq 2$ PGSI negative consequence items.

${ }^{c}$ Endorsement of $\geq 2$ SGHS items.

${ }^{\mathrm{d}}$ Endorsement of $\geq 2$ PGSI negative consequence items or SGHS items across any domain of harm.

${ }^{\mathrm{e}}$ Endorsement of $\geq 2$ PGSI negative consequence items or SGHS items across different domains of harm.

\section{Any-domain and cross-domain definitions of harm}

Given the similarities between the results obtained using PGSI-Harm and SGHS-Harm (optimal low-risk limits, proportions exceeding limits, absolute and risk ratio estimates), the PGSI negative consequence items and SGHS items were pooled to explore the effect of using a definition of harm in which at least two harms across different domains are endorsed on the low-risk limits. The low-risk gambling limits were all acceptable using both Any-domainHarm and Cross-domain-Harm (with all displaying moderate classification accuracy), with one exception (Any-domain-Harm gambling expenditure as a proportion of income limit) (Table 4).

Any-domain-Harm was exceeded by $7.3 \%$ of gamblers and $4.2 \%$ of the population. Using this definition, the overall limits were exceeding any of the following: gambling frequency of 29 times per year; gambler expenditure of 
Table 5. ROC analyses for each gambling activity using PGSI-Harm ${ }^{\mathrm{a}}$

\begin{tabular}{|c|c|c|c|c|c|c|c|c|}
\hline & EGMs & $\begin{array}{c}\text { Horse/dog } \\
\text { racing }\end{array}$ & $\begin{array}{l}\text { Instant } \\
\text { scratch } \\
\text { tickets }\end{array}$ & Lottery & Keno & $\begin{array}{l}\text { Casino } \\
\text { table } \\
\text { games }\end{array}$ & Bingo & $\begin{array}{c}\text { Sports/ } \\
\text { other event } \\
\text { betting }\end{array}$ \\
\hline $\begin{array}{l}\text { Proportion of } \\
\text { gamblers on } \\
\text { the specific } \\
\text { gambling }\end{array}$ & $\begin{array}{c}10.13 \% \\
(95 \% \mathrm{CI} \\
7.58 \\
13.41)\end{array}$ & $\begin{array}{c}8.19 \% \\
(95 \% \mathrm{CI} \\
5.16 \\
12.77)\end{array}$ & $\begin{array}{c}5.88 \% \\
(95 \% \text { CI } \\
3.96,8.63)\end{array}$ & $\begin{array}{c}3.30 \% \\
(95 \% \mathrm{CI} \\
2.41,4.51)\end{array}$ & $\begin{array}{c}5.91 \% \\
(95 \% \mathrm{CI} \\
4.30,8.05)\end{array}$ & $\begin{array}{c}11.72 \% \\
(95 \% \mathrm{CI} \\
6.71 \\
19.68)\end{array}$ & $\begin{array}{c}3.22 \% \\
(95 \% \mathrm{CI} \\
0.56 \\
16.55)\end{array}$ & $\begin{array}{c}15.45 \% \\
(95 \% \mathrm{CI} \\
8.51 \\
26.40)\end{array}$ \\
\hline
\end{tabular}

activity

exceeding

the

definition of

harm

Gambling

frequency

per year

Cut-off AUC (95\%

CIs)

11

$0.66(0.57$,

$0.75)$

16

6

$\mathbf{0 . 7 6}(\mathbf{0 . 6 5}, \quad 0.60(0.49, \quad 0.48(0.38$

$0.87)$

$0.71)$

$0.58)$

11
0.73

(0.65,

$0.81)$

Sensitivity, specificity

$N$
Absolute
risk

Relative

risk

Gambling

expenditure

per year

AUC (95\%

CIs)

Sensitivity,

specificity

$N$
Absolute
risk

Relative

risk

Gambling

expenditure

a proportion

of gross

personal

income

duration per year

Session expenditure

Cut-off

AUC (95\%

CIs)

Sensitivity,

specificity

$N$
Absolute
risk

Relative

risk

Cut-off

AUC (95\%

CIs)

Sensitivity, specificity

$N$
Absolute
risk

Relative

$$
\text { risk }
$$

Cut-off AUC (95\%

$0.49,0.76$

$0.70,0.68$

$0.54,0.60 \quad 0.06,0.95$

$0.63,0.70$

\section{3}

457

18.6

901

2080

6.8

420

$0.65(0.54$

$0.76)$

$0.91)$

$0.71)$

$0.60)$

0.73

(0.65,

0.81)

1,101
12.0

4.1

$0.45,0.80$

$\mathbf{0 . 6 7 , 0 . 7 4} \quad 0.47,0.67 \quad 0.22,0.81$

761

441

896

2038

1,091

11.8

11.5

7.3

7.0

0.0

7.0

3.3

$0.65(0.59$,

$0.73(0.60$,

0.85)

$0.56(0.45$,

$0.71)$

$0.57,0.77$

$0.66)$

$0.58(0.50$

$0.63)$

$0.44,0.89$

384

759

1723

955

652

30.8

6.9

450

380

$-$

$-$

$-$

$0.64(0.54$,

$0.75)$

$0.82(0.74$,

$0.91)$

20

120

144

$0.46,0.77$

$0.79,0.71$

$0.67)$

$0.52(0.41$ 772

442874

$0.28,0.77$

772

19.2

874

1981

1,040

8.9

55

25

5

14

18

$0.61(0.50$

$\mathbf{0 . 7 2}(\mathbf{0 . 6 2}, \quad 0.53(0.43$

$$
\text { CIs) }
$$

$\begin{array}{ccc}450 & 52 & 728 \\ \mathbf{0 . 7 8}(\mathbf{0 . 6 4}, & 0.59(0.48, & 0.51(0.42,\end{array}$

$0.61,0.73$

0.0

14.0

5.7

$0.59(0.54$

$0.54(0.42$,

$0.68)$

$0.32(0.27$

$0.37)$

$0.69(0.53$,

141

64

$0.58,0.98$

$-$

-

113

240

30

$0.68(0.60$

$0.67(0.51$

$0.79(0.18$

$0.48)$

$.63(0.45$,

$0.63,0.63$

$0.82)$

$0.94,0.21$

153

79

114

150

80

25

$0.63(0.56$

$0.66(0.56$,

$0.53(0.32, \quad 0.04(0.00$

$0.74) \quad 0.25)$

.70 (0.51,

Sensitivity, specificity

$$
\text { N }
$$

769

444

$0.63)$

$0.70)$

$0.75)$

$0.28,0.80$

$0.00,0.96$

0.88)

$0.57,0.71$

116

(continued) 
Table 5. Continued

\begin{tabular}{|c|c|c|c|c|c|c|c|c|c|}
\hline & & EGMs & $\begin{array}{c}\text { Horse/dog } \\
\text { racing }\end{array}$ & $\begin{array}{l}\text { Instant } \\
\text { scratch } \\
\text { tickets }\end{array}$ & Lottery & Keno & $\begin{array}{l}\text { Casino } \\
\text { table } \\
\text { games }\end{array}$ & Bingo & $\begin{array}{c}\text { Sports/ } \\
\text { other event } \\
\text { betting }\end{array}$ \\
\hline & $\begin{array}{l}\text { Absolute } \\
\text { risk }\end{array}$ & - & 16.2 & - & - & - & - & - & 24.1 \\
\hline & $\begin{array}{l}\text { Relative } \\
\text { risk }\end{array}$ & - & 9.2 & - & - & - & - & - & 2.2 \\
\hline \multirow{6}{*}{$\begin{array}{l}\text { Session } \\
\text { duration }\end{array}$} & Cut-off & 60 & 25 & 5 & 4 & 25 & 150 & 45 & 20 \\
\hline & $\begin{array}{c}\text { AUC }(95 \% \\
\text { CIs })\end{array}$ & $\begin{array}{c}0.57(0.47 \\
0.67)\end{array}$ & $\begin{array}{c}0.72(0.61 \\
0.83)\end{array}$ & $\begin{array}{c}0.45(0.35 \\
0.56)\end{array}$ & $\begin{array}{c}0.57(0.49 \\
0.66)\end{array}$ & $\begin{array}{c}0.57(0.48 \\
0.66)\end{array}$ & $\begin{array}{c}0.60(0.41 \\
0.79)\end{array}$ & $\begin{array}{c}0.47(0.33 \\
0.61)\end{array}$ & $\begin{array}{c}0.64(0.42 \\
0.85)\end{array}$ \\
\hline & $\begin{array}{l}\text { Sensitivity, } \\
\text { specificity }\end{array}$ & $0.34,0.78$ & $0.70,0.62$ & $0.00,1.00$ & $0.48,0.63$ & $0.43,0.67$ & $0.38,0.84$ & $0.99,0.35$ & $0.49,0.71$ \\
\hline & $N$ & 781 & 449 & 885 & 1998 & 1,050 & 154 & 79 & 114 \\
\hline & $\begin{array}{l}\text { Absolute } \\
\text { risk }\end{array}$ & - & 15.4 & - & - & - & - & - & - \\
\hline & $\begin{array}{l}\text { Relative } \\
\text { risk }\end{array}$ & - & 4.7 & - & - & - & - & - & - \\
\hline
\end{tabular}

${ }^{a}$ Bold typeface indicates AUC $\geq 0.70$.

AUD $\$ 440$ per year; gambling duration of 353 minutes $(5 \mathrm{~h}$, $53 \mathrm{~min}$ ) per year; and 2 types of gambling activity per year. The proportion of gamblers who exceeded these limits and who reported harm ranged from 10.6 to $18.9 \%$; while exceeding these limits was associated with a 2.8 -fold to 5.3-fold increase in the risk of experiencing harm, relative to gamblers who did not exceed the limits.

Cross-domain Harm was exceeded by $5.6 \%$ of gamblers and $3.3 \%$ of the population. Using this definition, the overall limits were exceeding any of the following: gambling frequency of 33 times per year; gambling expenditure of AUD\$501 per year; gambling expenditure comprising 9.8\% of gross personal income; gambling duration of 410 minutes ( $6 \mathrm{~h}, 50 \mathrm{~min})$ per year; and 2 types of gambling activity per year. The proportion of gamblers who exceeded these limits and who reported harm ranged from 9.9 to $30.4 \%$; while exceeding these limits was associated with a 3.3-fold to 8.0-fold increase in the risk of experiencing harm, relative to gamblers who did not exceed the limits.

\section{DISCUSSION}

\section{Comparison of PGSI and SGHS}

In this study, both PGSI-Harm and SGHS-Harm overall low-risk gambling limits produced acceptable ROC parameters, with all displaying similar moderate classification accuracy. PGSI-Harm and SGHS-Harm derived remarkably similar overall low-risk gambling limits, although the limits derived using PGSI-Harm were consistently slightly higher. They also captured very similar proportions of gamblers in the general population, suggesting that both sets of items are measuring harms of comparable severity; they also provided similar assessments of absolute and relative (ratio) risk. These similarities support the robustness of the limits derived in previous research using the PGSI as the measure of harm. Moreover, they are consistent with prior findings that diverse specific 'symptoms' of harm function as indicators of a single, unidimensional construct (Browne \& Rockloff, 2019a) and do not appear to support suggestions the SGHS is assessing trivial harms relative to the PGSI or opportunity costs, rather than bona fide personal impacts (Delfabbro \& King, 2019). However, while there was considerable overlap in those exceeding the low-risk limits using each definition of harm, PGSI-Harm and SGHS-Harm appear to classify respondents differently, with only onethird to one-half of respondents classified as true positive cases for both definitions of harm. This is of concern given that both the PGSI negative consequence items and SGHS items are intended to capture the same underlying construct of gambling-related harm. This finding highlights the need for further research exploring differences in true prevalence estimates when employing different operationalisations of gambling-related harm given the relatively low prevalence rates of problem gambling and gambling-related harm in the general population.

While the highest AUCs were identified for the limit relating to gambling expenditure, the highest relative (ratio) and absolute risks were identified for the limit relating to gambling expenditure as a proportion of income. These findings are consistent with the previous Australian study, which suggested that limits relating to gambling expenditure (gambling expenditure and gambling expenditure as a proportion of income) were consistently the best-performing (Dowling et al., 2021). Based on previous evidence (Dowling et al., 2021), promoting these gambling expenditure limits will likely identify gamblers who exceed other limits. The limits identified in the current study are generally at the lower end of the range identified in Canada (Currie et al., 2017; Currie et al., 2006; Currie, Hodgins, Wang, El-Guebaly, Wynne, et al., 2008; Currie et al., 2009) and elsewhere (Brosowski et al., 2015), but are very similar to the previous PGSI-based Tasmanian limits (Dowling et al., 2021). The exception is the gambling expenditure as a proportion of gross personal income limit. While this limit was very 
Table 6. ROC analyses for each gambling activity using SGHS-Harm ${ }^{\mathrm{a}}$

\begin{tabular}{|c|c|c|c|c|c|c|c|c|}
\hline & EGMs & $\begin{array}{l}\text { Horse/dog } \\
\text { racing }\end{array}$ & $\begin{array}{l}\text { Instant } \\
\text { scratch } \\
\text { tickets }\end{array}$ & Lottery & Keno & $\begin{array}{l}\text { Casino } \\
\text { table } \\
\text { games }\end{array}$ & Bingo & $\begin{array}{c}\text { Sports/ } \\
\text { other event } \\
\text { betting }\end{array}$ \\
\hline $\begin{array}{l}\text { Proportion of } \\
\text { gamblers on } \\
\text { the specific } \\
\text { gambling }\end{array}$ & $\begin{array}{c}9.84 \% \\
(95 \% \mathrm{CI} \\
7.52 \\
12.79)\end{array}$ & $\begin{array}{c}8.85 \% \\
(95 \% \mathrm{CI} \\
6.13 \\
12.61)\end{array}$ & $\begin{array}{c}6.54 \% \\
(95 \% \mathrm{CI} \\
4.64,9.14)\end{array}$ & $\begin{array}{c}5.06 \% \\
(95 \% \mathrm{CI} \\
3.94,6.48)\end{array}$ & $\begin{array}{c}6.91 \% \\
(95 \% \mathrm{CI} \\
5.24,9.05)\end{array}$ & $\begin{array}{c}13.59 \% \\
(95 \% \mathrm{CI} \\
8.65 \\
20.71)\end{array}$ & $\begin{array}{c}8.33 \% \\
(95 \% \mathrm{CI} \\
2.89 \\
21.70)\end{array}$ & $\begin{array}{c}16.97 \% \\
(95 \% \mathrm{CI} \\
10.35 \\
26.58)\end{array}$ \\
\hline
\end{tabular}

activity

exceeding

the

definition of

harm

Gambling

frequency

per year

Cut-off AUC (95\%

CIs)

11

$0.69(0.61$

24

$\begin{array}{lll}6 & 13\end{array}$

$0.77)$

0.72) 0.67$) \quad 0.61)$

11

0.71

$(0.65$

2

$0.57(0.45$,

$0.69)$

6

$0.73(0.49, \quad 0.53(0.34$,

0.78)

Sensitivity,

specificity

$N$
Absolute
risk

Relative

risk

Gambling

expenditure

per year

Cut-off

AUC (95\%

CIs)

$0.53,0.77$

$0.42,0.75 \quad 0.50,0.60 \quad 0.57,0.48$

0.61, $0.70 \quad 0.61,0.48$

$0.96)$

$0.72)$

781

456

899

2068

1,098

13.0

164

$\mathbf{0 . 7 5}, \mathbf{0 . 5 9} \quad 0.26,0.85$

$-$
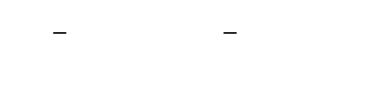

$\begin{array}{cccc}\mathbf{2 4 0} & 800 & 65 & 208 \\ \mathbf{0 . 7 4 ( 0 . 6 6 ,} & 0.60(0.48, & 0.57(0.46, & 0.56(0.49 \\ \mathbf{0 . 8 1}) & 0.73) & 0.67) & 0.64)\end{array}$

\section{3}

130

0.73

$(0.67$,

0.80)

Sensitivity,

specificity

$\mathrm{N}$
Absolute
risk

$0.64,0.70$

$0.38,0.80$

$0.38,0.72 \quad 0.56,0.53$

$0.64,0.70$

\section{1,088}

12.2

$894 \quad 2026$

759
18.4

440

$-$

$-$

3.4

Relative

risk

Gambling

expenditure

a proportion

of gross

personal

income

duration per

year

Cut-off

AUC (95\%

CIs)

Sensitivity,

specificity

$N$
Absolute
risk

Relative

risk

Cut-off

AUC (95\%

CIs)

Sensitivity,

specificity

$N$
Absolute
risk

$\begin{array}{cccr}7.3 & 9.6 & 0.0 & 6.7\end{array}$

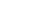

$-$

2.7

4.0

0.0

$48(0.46$

$0.71)$

84

16.7

126

$$
0.71)
$$

$0.64(0.53$

$48(0.39$

$.57(0.51$

$0.60(0.55$

$0.44(0.38$

$0.5)$

$0.79,0.37$

$0.64)$

$0.38,0.94 \quad 0.38,0.91$

141

652

383

757

1715

953

141
-

80

$\begin{array}{lrrrr}330 & 360 & 25 & 35 & 135\end{array}$

$\mathbf{0 . 7 0}(\mathbf{0 . 6 1}, \quad 0.63(0.51, \quad 0.55(0.45, \quad 0.56(0.49, \quad \mathbf{0 . 7 0}$

0.78) 0.74$) \quad 0.65) \quad 0.63)$

(0.64,

$0.77)$

$0.56(0.43$

$0.68)$

360

1,140

$\mathbf{0 . 5 7 , 0 . 7 2} \quad 0.51,0.67 \quad 0.37,0.71 \quad 0.61,0.48 \quad \mathbf{0 . 6 8 , 0 . 6 2}$

$0.72,0.37$

1,037

11.0

153

2.5

risk

Session

expenditure

AUC $(95 \%$

CIs)

34

5

specificity
13

16

25

30

0.71 (0.64, $0.61(0.50$

$0.53(0.44$

$0.63)$

$0.60(0.54$

$0.66)$

$0.68(0.60$

$0.76)$

$\mathbf{0 . 6 8 , 0 . 6 2} \quad 0.48,0.69 \quad 0.73,0.33 \quad 0.74,0.43 \quad 0.55,0.71 \quad 0.77,0.34$

$0.56(0.43$

$0.70)$

$\mathbf{0 . 6 8 , 0 . 6 2} \quad 0.48,0.69 \quad 0.73,0.33 \quad 0.74,0.43 \quad 0.55,0.71 \quad 0.77,0.34$

$0.93)$

$20 \quad 20$

$9(0.65, \quad 0.64(0.48$

$0.58,0.62$

(continued) 
Table 6. Continued

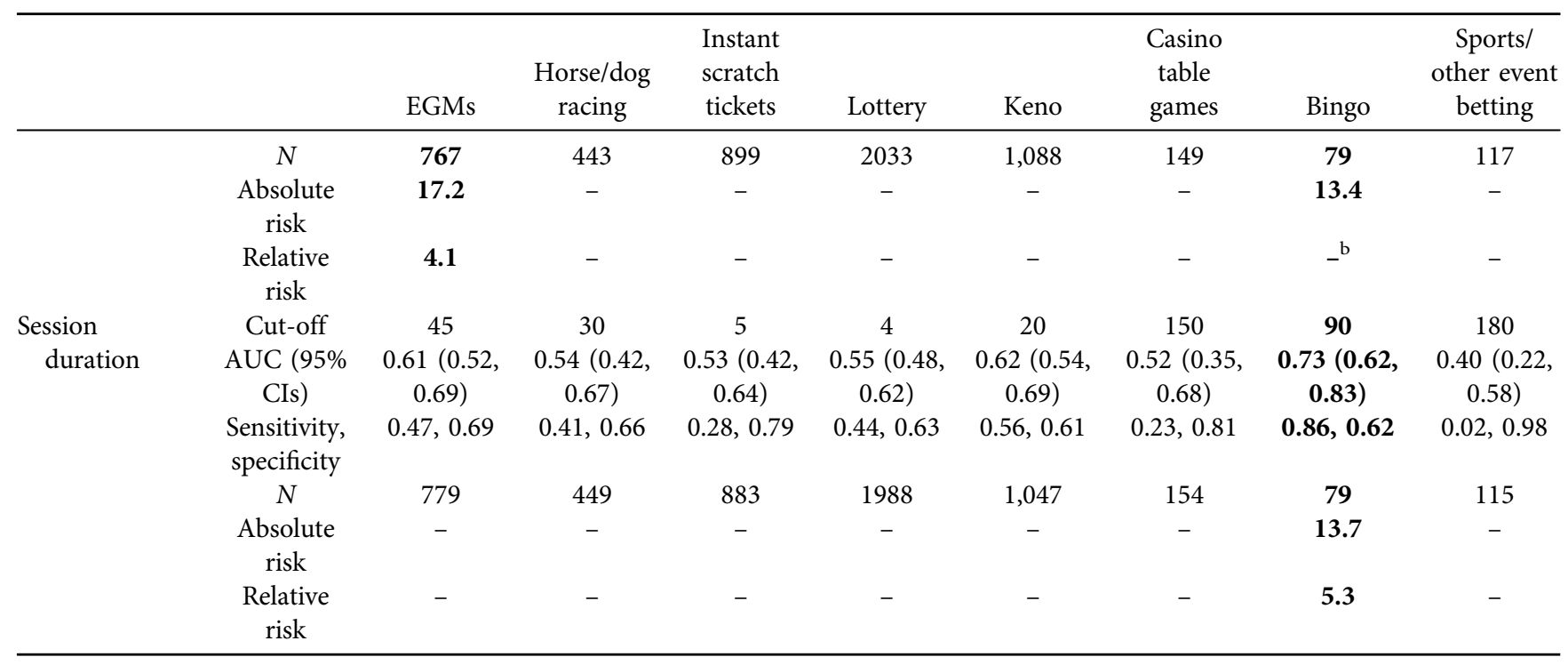

${ }^{a}$ Bold typeface indicates AUC $\geq 0.70$.

${ }^{\mathrm{b}}$ No relative risk estimate available as none of the gamblers not exceeding the limit endorsed gambling-related harm on the SGHS.

similar for PGSI-Harm and SGHS-Harm (10.2 and 10.3\%, respectively), it is considerably higher in this study than in the previous study (1.7\%). Given that the gambling expenditure limit is very similar across these studies, the most likely explanation is the use of very refined personal gross income categories, which were deliberately introduced into the fourth SEIS for the purposes of these analyses (Dowling et al., 2021). Given that this limit is consistently well-performing and may be preferable to the absolute expenditure limit as it provides a standardised index that is not confounded by annual income (Currie et al., 2017; Dowling et al., 2021; Weinstock, Ledgerwood, \& Petry, 2007), future research replicating this limit using more refined income categories is required.

Not all activity-specific limits identified using both PGSIHarm and SGHS-Harm displayed acceptable classification accuracy, which is consistent with previous research (Brosowski et al., 2015; Quilty et al., 2014). This is likely due to relatively lower involvement on some specific gambling activities, as well as the inability to link gambling-related harm to specific gambling activities due to the use of a global measure of harm. Limits were identified for horse/dog racing, keno, and sports/other betting using PGSI-Harm; and for EGM gambling, keno, and bingo using SGHS-Harm. Only the bingo-specific expenditure and session duration limits can be compared to previous research, both of which were lower than those previously identified in Canada (Quilty et al., 2014). These differences are likely because of the smaller sample sizes in the current dataset than in previous research (Brosowski et al., 2015; Quilty et al., 2014). The PGSI-Harm and SGHS-Harm keno limits, however, were very similar. Taken together, these findings highlight the need for further research evaluating activity-specific limits for Australia using larger population-representative studies.

\section{Effect of defining harms across different domains}

It is generally agreed that gambling harm occurs on a continuum from mild to severe (Browne \& Rockloff, 2019b). However, for the pragmatic purpose of setting low-risk gambling limits using a risk ratio approach, it is necessary to adopt a threshold which defines an unacceptable level of harm. In the absence of consensus on where this limit lies, the effect of using a definition of harm in which at least two harms across different domains were endorsed was explored using the pool of PGSI negative consequence and SGHS items. Although Cross-domain-Harm produced more robust and consistently higher limits, and was exceeded by slightly fewer gamblers, than Any-domain-Harm, the requirement that gamblers endorse harms across at least two different domains of harm had a relatively negligible effect. Moreover, the limits were very similar to those identified using PGSIHarm and SGHS-Harm. Taken together, these findings are consistent with previous findings that, when using a risk ratio approach, low-risk gambling limits are generally robust to methodological variations in operationalising harm, suggesting that different harm outcomes index similar constructs (Brosowski et al., 2015; Currie et al., 2006; Currie, Hodgins, Wang, El-Guebaly, Wynne, et al., 2008; Currie et al., 2009).

\section{Study limitations and future research}

There has been considerable recent debate regarding the measurement of gambling-related harm that is useful to inform public policy and regulation (Angus, Anjoul, Shannon, \& Blaszczynski, 2019; Delfabbro \& King, 2019) and validated and interpretable measures have been slow to develop. Although it is the most widely employed measure of gambling harm, the SGHS only includes items across a limited number of domains, although scale scores appear to capture well the index of gambling-related harm assessed by 
the full 72-item checklist. The SGHS has also been criticised on the grounds that it fails to differentiate between opportunity cost and general harm and may encourage an overestimation of the degree of harm experienced by lower-risk gamblers (Delfabbro \& King, 2019). Future research replicating these findings using alternative instruments as they emerge (Quilty, Watson, \& Bagby, 2015; Shannon, Anjoul, \& Blaszczynski, 2017) or more objective indicators of harm (Dowling et al., 2021) is therefore recommended. The robustness of the limits across measures suggests that using either measure is appropriate, although they appear to classify respondents differently in terms of true positives. Given that gambling-related harm is understood as on a continuum ranging from negligible to extreme, however, an ideal additive measure would comprise a linear metric scale, in which there are equal differences in magnitude between scores, which represent equal differences on decrements to health and wellbeing. While it is likely that the SGHS is superior to the PGSI in approximating these decrements, research validating harms-based measures on a metric scale is required.

More broadly, this research provides an important step in refining low-risk gambling limits when using a risk ratio approach, which has been employed by all of the available literature, to date. This approach, however, requires the selection of a somewhat arbitrary threshold for gambling-related harm, suggesting that a reasonable approach may be to identify a robust estimate over multiple samples that explicates where harms reliably exceed any recreational benefits from gambling (Rockloff, Browne, Russell, Merkouris, \& Dowling, 2019) or to examine thresholds that are associated with a non-negligible expected decrement to health and wellbeing. Alternatively, like low-risk drinking limits (NHMRC, 2020; Rehm, Room, \& Taylor, 2008; Room \& Rehm, 2012), lowrisk gambling limits could be made on the basis of the amount of absolute risk that can be tolerated (Dowling et al., 2021; Markham, Young, \& Doran, 2016). Previous findings that gambling risk (dose-response) curves are either $\mathrm{r}$-shaped or linear rather than J-shaped (Dowling et al., 2018; Markham et al., 2016) and that gambling consumption lower than the low-risk limits also confers a considerable degree of risk (Dowling et al., 2021) raise questions regarding the degree to which there is any level of gambling behaviour that is not associated with harm (Dowling et al., 2021; Markham et al., 2016). However, further research determining the amount of tolerable absolute risk from gambling (Rehm, Lachenmeier, \& Room, 2014), as well as the actual shape of gambling risk curves (Currie et al., 2017; Markham et al., 2016), is required before absolute risk methods can be employed to identify low-risk gambling limits (Dowling et al., 2021).

Other limitations of this research include the underrepresentation of younger adults, use of self-reported measures of gambling involvement, the inability to link gambling-related harms to specific gambling activities, and the reduced sample sizes for analysing each game separately.
Further research is required to identify a consistent set of gambling activity-specific limits.

\section{Study implications}

This study advances the currently available literature by deriving limits using a measure of harms attributable to gambling. The similarity in the limits identified using the PGSI and the SGHS suggest that previous PGSI-based limits are robust data-derived thresholds that provide important information about an individual's risk for experiencing harm based on their gambling consumption. The current study also replicates the overall limits identified in Australia (Dowling et al., 2021), suggesting that they could serve as working guidelines for the consideration of gambling stakeholders to usefully augment the currently available behavioural 'responsible gambling' guidelines. Low-risk limits can allow consumers to make informed choices about personal risk; serve as a cost-effective screening method for identifying people at higher-risk for gambling-related harm; monitor the prevalence of gambling-related harm in population-level research; investigate the efficacy of secondary intervention efforts; and be applied in tertiary intervention settings for gamblers selecting a moderation goal (Currie et al., 2017; Currie et al., 2011; Currie et al., 2006; Currie, Hodgins, Wang, El-Guebaly, Wynne, et al., 2008; Currie et al., 2009; Quilty et al., 2014; Weinstock et al., 2007).

\section{CONCLUSION}

This study was designed in response to criticisms that lowrisk gambling limits have exclusively been derived using item subsets of problem gambling severity measures. The findings suggest that the overall limits identified using the PGSI, the most commonly employed measure of problem gambling severity, and the SGHS, a measure specifically designed to measure the harms attributable to gambling, are similar and that the requirement that gamblers endorse harms across different domains of harm had a relatively negligible effect on these limits. Although replication using instruments that measure harm across additional domains is required, the findings suggest that previous PGSI-based limits are robust thresholds that have considerable potential utility in the prevention of gambling-related harm.

Funding sources: The study involved the analysis of data collected for the Fourth Social and Economic Impact Study of Gambling in Tasmania, which was funded by the Tasmanian Government Department of Treasury and Finance.

Authors' contribution: ND conceptualised and designed the study. CG and GY were involved in data preparation, statistical analysis, and interpretation of data. ND, SM, GY, $\mathrm{MB}, \mathrm{MR}$ and PM obtained funding. ND wrote the first draft of the manuscript and all authors have read and agreed to the published version of the manuscript. All authors had full 
access to all data in the study and take responsibility for the integrity of the data and the accuracy of the data analysis.

Conflicts of Interest: The authors have no conflicts of interest to declare in relation to this article. The 3-year declaration of interest statement of this research team is as follows: ND, $\mathrm{SM}, \mathrm{GY}, \mathrm{MB}, \mathrm{MR}$ and PM have received funding from multiple sources, including government departments and the Victorian Responsible Gambling Foundation (through hypothecated taxes from gambling revenue). ND, SM and GY have also received funding from the National Association for Gambling Studies (NAGSs), a not-for-profit organisation with individual members across all stakeholder groups, which derives its funding from member fees and conference proceeds. ND and SM have also received funding from the International Center for Responsible Gaming (ICRG), a charitable organisation, which derives its funding from through contributions from multiple stakeholder groups (with funding decisions the responsibility of an independent scientific advisory board). ND is the recipient of a Deakin University Faculty of Health Mid-Career Fellowship. SM is the recipient of a New South Wales Office of Responsible Gambling Postdoctoral Fellowship and has formerly been the Victorian state representative (unpaid) on the NAGS Executive Committee. None of the authors have knowingly received research funding from the gambling, tobacco, or alcohol industries or any industry-sponsored organisation.

\section{REFERENCES}

ACIL Allen, Deakin University, Central Queensland University, \& Social Research Centre. (2017). Fourth social and economic impact study of gambling in Tasmania. Tasmania: Tasmanian Department of Treasury and Finance.

American Association of Public Opinion Research. (2011). Standard definitions: final disposition of case codes and outcome rates for surveys (7 ed.). AAPOR.

Angus, D. J., Anjoul, F., Shannon, K., \& Blaszczynski, A. (2019). Gambling related harms - Community and clinical comparisons. Addiction Research \& Theory, 28(3), 194-203. https://doi. org/10.1080/16066359.2019.1622001.

Brosowski, T., Hayer, T., Meyer, G., Rumpf, H. J., John, U., Bischof, A., et al. (2015). Thresholds of probable problematic gambling involvement for the German population: Results of the pathological gambling and epidemiology (PAGE) study. Psychology of Addictive Behaviors, 29(3), 794-804. https://doi.org/10.1037/ adb0000088.

Browne, M., Goodwin, B. C., \& Rockloff, M. J. (2018). Validation of the Short gambling harm screen (SGHS): A tool for assessment of harms from gambling. Journal of Gambling Studies, 34(2), 499-512. https://doi.org/10.1007/s10899-017-9698-y.

Browne, M., \& Rockloff, M. J. (2017). The dangers of conflating gambling-related harm with disordered gambling. Journal of Behavioral Addictions, 6(3), 317-320. https://doi.org/10.1556/ 2006.6.2017.059.
Browne, M., \& Rockloff, M. J. (2019a). Measuring behavioural dependence in gambling: A case for removing harmful consequences from the assessment of problem gambling pathology. Journal of Gambling Studies. https://doi.org/10.1007/s10899019-09916-2.

Browne, M., \& Rockloff, M. J. (2019b). Measuring harm from gambling and estimating its distribution in the population. In H. Bowden-Jones, C. Dickson, C. Dunand \& O. Simon (Eds.), Harm reduction for problem gambling: A public health approach. Routledge.

Casswell, S. (2012). Why have guidelines at all? A critical perspective. Drug and Alcohol Review, 31(2), 151-152. https:// doi.org/10.1111/j.1465-3362.2011.00376.

Currie, S. R., Hodgins, D. C., \& Casey, D. M. (2013). Validity of the problem gambling severity index interpretive categories. Journal of Gambling Studies, 29(2), 311-327. https://doi.org/10. 1007/s10899-012-9300-6.

Currie, S. R., Hodgins, D. C., Casey, D. M., El-Guebaly, N., Smith, G. J., Williams, R. J., et al. (2017). Deriving low-risk gambling limits from longitudinal data collected in two independent Canadian studies. Addiction, 112(11), 2011-2020. https://doi. org/10.1111/add.13909.

Currie, S. R., Hodgins, D. C., Casey, D. M., el-Guebaly, N., Smith, G. J., Williams, R. J., et al. (2011). Examining the predictive validity of low-risk gambling limits with longitudinal data. Addiction, 107(2), 400-406. https://doi.org/10.1111/j.13600443.2011.03622.x.

Currie, S. R., Hodgins, D. C., Wang, J., El-Guebaly, N., \& Wynne, H. (2008). In pursuit of empirically based responsible gambling limits. International Gambling Studies, 8(2), 207-227. https:// doi.org/10.1080/14459790802172265.

Currie, S. R., Hodgins, D. C., Wang, J., El-Guebaly, N., Wynne, H., \& Chen, S. (2006). Risk of harm among gamblers in the general population as a function of level of participation in gambling activities. Addiction, 101(4), 570-580. https://doi.org/10.1111/j. 1360-0443.2006.01392.x.

Currie, S. R., Hodgins, D. C., Wang, J., El-Guebaly, N., Wynne, H., \& Miller, N. V. (2008). Replication of low-risk gambling limits using canadian provincial gambling prevalence data. Journal of Gambling Studies, 24(3), 321-335. https://doi.org/10.1007/ s10899-008-9091-y.

Currie, S. R., Miller, N., Hodgins, D. C., \& Wang, J. L. (2009). Defining a threshold of harm from gambling for population health surveillance research. International Gambling Studies, 9(1), 19-38. https://doi.org/10.1080/14459790802652209.

Davern, M., Rodin, H., Beebe, T. J., \& Call, K. T. (2005). The effect of income question design in health surveys on family income, poverty and eligibility estimates. Health Services Research, 40(5), 1534-1552. https://doi.org/10.1111/j.1475-6773.2005. 00416.x.

Delfabbro, P., \& King, D. L. (2019). Challenges in the conceptualisation and measurement of gambling-related harm. Journal of Gambling Studies, 35(3), 743-755. https://doi.org/10. 1007/s10899-019-09844-1.

Dowling, N., Greenwood, C., Merkouris, S., Youssef, G., Suomi, A., \& Room, R. (2018). The identification of empirically derived Australian responsible gambling limits. In Report prepared for the Victorian Responsible Gambling Foundation. 
Dowling, N. A., Youssef, G. J., Greenwood, C., Merkouris, S. S., Suomi, A., \& Room, R. (2021). The development of empirically derived Australian low-risk gambling limits. Journal of Clinical Medicine, 10, 167. https://doi.org/10.3390/jcm10020167.

Ferris, J., \& Wynne, H. (2001). The Canadian problem gambling index: Final report. Ottawa, ON: Canadian Centre on Substance Abuse.

Kim, S., Egerter, S., Cubbin, C., Takahashi, E. R., \& Braveman, P. (2007). Potential implications of missing income data in population-based surveys: An example from a postpartum survey in California. Public Health Reports, 122(6), 753-763. https:// doi.org/10.1177/003335490712200607.

Korn, D. A., \& Shaffer, H. J. (1999). Gambling and the health of the public: Adopting a public health perspective. Journal of Gambling Studies, 15(4), 289-365.

Langham, E., Thorne, H., Browne, M., Donaldson, P., Rose, J., \& Rockloff, M. (2016). Understanding gambling related harm: a proposed definition, conceptual framework, and taxonomy of harms. BMC Public Health, 16, 80. https://doi.org/10.1186/ s12889-016-2747-0.

Markham, F., Young, M., \& Doran, B. (2016). The relationship between player losses and gambling-related harm: Evidence from nationally representative cross-sectional surveys in four countries. Addiction, 111, 320-330. https://doi.org/10.1111/add. 13178.

National Health and Medical Research Council [NHMRC]. (2020). Australian guidelines to reduce health risks from drinking alcohol. Canberra: Commonwealth of Australia.

Neal, P., Delfabbro, P., \& O’Neil, M. (2005). Problem gambling and harm: toward a national definition. Melbourne: Office of Gaming and Racing.

Quilty, L. C., Avila Murati, D., \& Bagby, R. M. (2014). Identifying indicators of harmful and problem gambling in a Canadian sample through receiver operating characteristic analysis. Psychology of Addictive Behaviors, 28(1), 229-237. https://doi.org/ 10.1037/a0032801.
Quilty, L. C., Watson, C., \& Bagby, M. R. (2015). CPGI-population harm: A supplement to the Canadian problem gambling index. Canadian Journal of Addiction, 6(2), 20-28.

Rehm, J., Lachenmeier, D. W., \& Room, R. (2014). Why does society accept a higher risk for alcohol than for other voluntary or involuntary risks? BMC Medicine, 12, 1-6.

Rockloff, M. J., Browne, M., Russell, A. M. T., Merkouris, S. S., \& Dowling, N. A. (2019). A quantification of the net consumer surplus from gambling participation. Journal of Gambling Studies, 35(4), 1147-1162. https://doi.org/10.1007/s10899-019-09845-0.

Room, R., \& Rehm, J. (2012). Clear criteria based on absolute risk: Reforming the basis of guidelines on low-risk drinking. Drug and Alcohol Review, 31(2), 135-140. https://doi.org/10.1111/j. 1465-3362.2011.00398.x.

Ruopp, M. D., Perkins, N. J., Whitcomb, B. W., \& Schisterman, E. F. (2008). Youden Index and optimal cut-point estimated from observations affected by a lower limit of detection. Biometrical Journal, 50(3), 419-430. https://doi.org/10.1002/ bimj.200710415.

Shannon, K., Anjoul, F., \& Blaszczynski, A. (2017). Mapping the proportional distribution of gambling-related harms in a clinical and community sample. International Gambling Studies, 17(3), 366-385. https://doi.org/10.1080/14459795.2017. 1333131.

StataCorp. (2015). Stata: Release 14.1. Statistical software. College Station, TX: StataCorp LP.

Swets, J. A., Dawes, R. M., \& Monahan, J. (2000). Psychological science can improve diagnostic decisions. Psychological Science in the Public Interest, 1(1), 1-26. https://doi.org/10.1111/15291006.001.

Weinstock, J., Ledgerwood, D. M., \& Petry, N. M. (2007). Association between posttreatment gambling behavior and harm in pathological gamblers. Psychology of Addictive Behaviors, 21(2), 185-193. https://doi.org/10.1037/0893-164X.21.2.185.

Youden, W. J. (1950). Index for rating diagnostic tests. Cancer, 3, 32-35. https://doi.org/10.1002/1097-0142. 